\title{
¿Yo, hombre? Las masculinidades y el ser hombre en un programa reeducativo contra la violencia en México $^{2}$
}

\author{
I am a man? Masculinities and Being a Man in a \\ Reeducation Program Against Violence in Mexico.
}

\begin{abstract}
RESUMEN
A partir de una serie de entrevistas y grupos focales con hombres participantes del programa CECEVIM-GENDES, se pretende reflexionar sobre la percepción que tienen éstos sobre el ser hombre. Para ello, se decidió realizar el análisis a través de la propuesta teórica de Estela Serret $(2001,2011)$, quien propone tres niveles de análisis para la categoría género: simbólico, imaginario social, subjetivo. Desde esta perspectiva y en conjunto con algunos otros planteamientos de los estudios de género con enfoque en masculinidades, se identificó que: pese a que los usuarios logran realizar procesos introspectivos y retrospectivos sobre los orígenes de sus comportamientos violentos en el plano subjetivo, éstos ven dificultado su proceso de cambio debido al peso del imaginario social y de lo simbólico. Esta situación no permite construir formas alternativas de prácticas masculinas por el miedo constante a que estos posibles cambios terminen feminizándolos.
\end{abstract}

Palabras clave: masculinidades, ser hombre, género, violencia, méxico.

\section{Abstract}

The series of interviews and focus groups with male participants in the CECEVIMGENDES program serves to reflect on each individual's perception of what it means to be a man. The study was carried out utilizing Estela Serret's theoretical methodology for gender analysis, focusing on three distinct tiers: the symbolic, the imaginary, and the subjective. Through this lens along with other gender analysis approaches that focus on masculinities, the following was identified: users are able to reflect introspectively and retrospectively on the origins of their violent behaviors on a personal level, however, they often face difficulties in changing these behaviors due to the barriers that both the collective consciousness and the stereotypes pose. The combination of the two do not allow for the construction of alternative forms of masculinities as there is the constant fear that these potential changes will end up feminizing those that pursue such practices.

Keywords: Masculinities; Being a man, Gender, Violence, Mexico.

\section{SUMARIO}

1.- Introducción. 2.- Reporte metodológico. 3.- Ser hombre y las masculinidades. 4.Apuntes sobre el estudio de la(s) masculinidad(es). 5.- Los hombres y las masculinidades en México. 6.- Análisis de los resultados. 7.- Discusión desde la propuesta de Estela Serret. 8.- Conclusiones -Bibliografía.

1 Consultor independiente, Colaborador en Género y Desarrollo A.C (Gendes A.C), Profesor externo por la Universidad de Alicante, leamsiuy@gmail.com

2 Se agradece el aporte y apoyo para este trabajo de Daniel González Marín y René López Pérez. 


\section{1.- Introducción}

La violencia que ejercen los hombres contra sus parejas mujeres en todo el mundo, se ha vuelto un tema importante en la agenda política de muchos países. Entender que dicho suceso tiene un carácter público que escapa de lo privado del hogar, ha llevado a que paulatinamente se implementen políticas públicas, así como programas de asociaciones civiles o privadas, con el fin de buscar erradicar este problema que lleva a que uno de los lugares de mayor riesgo de muerte para una mujer sea su hogar y la principal amenaza sea su pareja o ex pareja (ONU Mujeres, 2017)

En México la situación de violencia contra las mujeres es dramática; el nivel de feminicidios, violaciones y acoso contra las mujeres han ido en aumento en los últimos años, fomentando la implementación de políticas especialmente dirigidas como lo es la Ley general de acceso de las mujeres a una vida libre de violencia ${ }^{3}$ (Lagarde y de los Rios, 2007). Esta situación a su vez, se encuentra sumergida en un contexto de violencia generalizada que lamentablemente vive el país en las últimas décadas, principalmente desde el inicio de la llamada «guerra contra el narco» iniciada por el ex presidente Calderón, produciéndose un aumento de los homicidios y personas desaparecidas en todo el territorio (Benítez Manuat, Rodríguez Luna y Quintanar Jiménez, 2018).

Como parte de los distintos esfuerzos públicos y privados que existen en el país para tratar el tema de la violencia contra las mujeres, en la Ciudad de México la asociación civil GENDES (Género y desarrollo) empezó desde 2003 a trabajar con hombres con el fin de que éstos erradiquen sus violencias. Uno de sus proyectos es el Programa CECEVIM-GENDES [PCG], que es llevado a cabo en forma continua desde el 2009 con el objetivo principal de reeducar desde una perspectiva de género, a hombres que hayan ejercido algún tipo de violencia contra sus parejas y/o hijas(os). El programa funciona mediante el modelo CECEVIM, creado por Antonio Ramírez, quien recoge la estructura del modelo MenAlive en los EEUU ${ }^{4}$. En este contexto, el presente artículo expone algunos resultados de una investigación de carácter interno, que en este caso tiene el objetivo principal de identificar la percepción que tienen los usuarios del PCG sobre lo que significa «ser un hombre» y cómo ésta influye en el proceso reeducativo de éstos. A este objetivo principal se le adhieren los siguientes objetivos específicos: (1) a partir de la propuesta de Estela Serret, identificar los componentes simbólicos, del imaginario social y del imaginario subjetivo, que están presentes en la percepción del ser un hombre como una categoría de género; (2) identificar las principales características que los participantes remarcan de lo que significa ser un hombre.

La estructura del artículo presentará en primera instancia: unas notas metodológicas, para después recuperar parte del debate teórico en cuanto a la diferenciación entre el concepto de ser hombre y el de masculinidad(es), así como

3 Ley publicada en el diario oficial de la Federación el 1 de febrero de 2007.

4 Ver más en: vargas-URías, Mauro Antonio (2009). Propuesta de lineamientos para la atención y reeducación de hombres agresores, a partir del diagnóstico sobre los modelos de intervención en México. Ciudad de México. 
también algunos aspectos importantes de los estudios sobre los mismos y de la especificidad que existe en México sobre el tema. Posteriormente, se corresponde al análisis del discurso de los entrevistados, presentando cinco categorías discursivas surgidas en las entrevistas y los grupos. Luego, se corresponde al análisis desde la perspectiva de lo propuesto por Estela Serret $(2001,2011)$, profundizando esos discursos en los niveles simbólicos, del imaginario social y subjetivo. Finalizando con la discusión y conclusiones.

\section{2.- Reporte metodológico}

El presente ensayo, se enmarca dentro de una investigación cualitativa de carácter interno, realizada por quien escribe en GENDES A.C ${ }^{5}$ en el transcurso de abril-octubre de 2018. Esta investigación tenía como fin principal identificar qué motiva a un participante del PCG a adherirse o desertar del mismo. Con tal fin, se decidió realizar una serie de grupos focales y entrevistas en profundidad con un total de 34 usuarios y ex usuarios del mismo, siguiendo criterios de muestreo opinático, donde los participantes fueron seleccionados mediante criterios estratégicos de conveniencia según el conocimiento y las posibilidades de convocatoria existentes con la población que se adecuaba a los criterios de la investigación (Ruiz Olabuénaga, 1999). Para el presente ensayo, se decidió trabajar con aquellos participantes de larga y mediana duración, que suman un total de 13 usuarios. Los motivos de trabajar únicamente con ellos, se deben a que son quienes tienen un mayor recorrido en el programa, entendiéndose que la participación en el programa podría influir en mayor grado en la percepción que tienen de lo que significa ser un hombre.

Del trabajo con estos usuarios, se recoge para la presente investigación, todo aquello que haya surgido en los discursos en cuanto a la identidad masculina o el ser hombre. Como parte de la metodología empleada, al final de las sesiones se hacían una serie de preguntas de carácter reflexivo, en donde una de ellas puntualmente hacía la pregunta de tinte esencialista: «¿qué significa ser un hombre para ustedes?». A partir de esta pregunta y en conjunto con algunas otras menciones que surgieron relacionadas con este tema a lo largo de los grupos y entrevistas, es que el presente ensayo reflexiona teóricamente acerca de las nociones sobre la masculinidad y el ser hombre en un grupo reeducativo para hombres que deciden trabajar sus violencias.

Los 13 participantes de los cuales se recogen sus relatos en el presente artículo, asistían durante el proceso de investigación al PCG. La selección de los usuarios se realizó mediante criterios de conveniencia, invitándose a aquellos sujetos que se entendían adecuados para los objetivos de la investigación, decidiéndose trabajar con estos 13 tras ser cumplidos los criterios de saturación discursiva (Valles, 1999); 6 de ellos son considerados de larga duración (entre 1 y 3 años) y los otros 7 de media duración (de 6 meses a 1 año). De los 13 participantes, 12 de ellos acudieron 
al programa por presentar problemas con su pareja, siendo que solo uno de éstos tenía una denuncia judicial por violencia doméstica, el resto en tanto, llegó por sugerencia de la pareja ante hechos de violencia no denunciados, mientras que solamente 1 entrevistado afirma acudir por motivos propios. De éstos, 4 han terminado su relación de pareja durante su participación en GENDES. Sus edades van desde los 28 a los 61 años y todos ellos se adscriben como heterosexuales, siendo todas sus (ex)parejas mujeres.

Para el análisis de los grupos y la entrevista se realizó un análisis de discurso basado en la perspectiva de Miguel Valles (1999) que permite identificar la percepción de los entrevistados, a través de las experiencias vividas y/o absorbidas, de lo que significa para ellos ser un hombre. Se es consciente que este discurso está cargado de subjetividades, por lo cual no se busca un significado objetivo, sino un significado narrado y generalizado de lo que ellos creen que hay que ser y hacer para ser un hombre en sus contextos particulares (Alonso, 2007)

\section{3.- Ser hombre y las masculinidades}

Uno de los inconvenientes con los que se encontró la investigación en sus inicios, fue el cómo trabajar la categoría masculinidad(es) en conjunto con el ser hombre. Se comparte la crítica de Amuchástegui (2007), en cuanto a que el concepto de masculinidad(es) se ha trabajado como una cosa-en-sí-misma, generando resultados diversos y erráticos, debido a que se han unificado las prácticas corporales de los seres humanos pertenecientes al sexo biológico masculino, con la masculinidad como estructura, proceso social y subjetividad. Esta situación, produce según la misma autora, que se genere confusión al hablar de hombre-masculinidad de la misma manera que se ha hecho con mujer-género.

Para Connell (1995), la masculinidad es al mismo tiempo un lugar en las relaciones de género, las prácticas a través de las que hombres y mujeres se relacionan y los efectos que éstas tienen en la experiencia corporal, en la personalidad y en la cultura. En tal sentido, la masculinidad no es propiedad de los hombres, ya que no se deriva automáticamente de una corporalidad; al igual que los hombres, una mujer también produce y reproduce la masculinidad. La relación entre el ser hombre y la(s) masculinidad(es), se puede entender a partir de lo planteado por Gilmore (1994), en cuanto afirma que la masculinidad sería la forma aceptada de ser de un hombre adulto en una sociedad concreta. Gutmann (2000) por su parte, comenta que la masculinidad estaría relacionada con «lo que los hombres dicen y hacen para ser hombres y no solo en lo que los hombres dicen y hacen» (:43). Olavarria (2006), entiende al ser hombre como una serie de prácticas que validan al sexo biológico. Salguero Velázquez (2013) identifica a la masculinidad como una identidad performativa que varía en tiempo y contexto. Guasch (2008) afirma que la masculinidad está compuestas de significados normativos: lo adecuado y lo inadecuado para ser considerado como hombre. Serret (2011) por su parte, complejiza el debate al realizar una crítica en cuanto a la rigidez con la cual se maneja la categoría género, principalmente a la dificultad que existe para el análisis de la identidad desde 
dicha perspectiva. Para la autora, existen tres niveles de análisis de la categoría género: simbólico; imaginario social; imaginario subjetivo. Con estos tres niveles, la autora muestra que la categoría género es transversal y transcurre desde lo macro social e histórico, a lo micro individual contextual, relacional y subjetivo, por lo que es necesario remarcar de qué nivel se está hablando cuando se hace referencia a la categoría género masculinidades ${ }^{6}$.

De esta manera, definimos a la masculinidad como: una serie de simbolismos, estereotipos e imaginarios sociales que son dinámicos, contextuales e históricos, que se fundan en el sistema sexo-género, que dicotomiza el mundo social entre lo masculino y femenino, jerarquizándolo, dejando a lo masculino en lo central y lo femenino en lo periférico, que no se circunscriben al ser hombre, ni al sexo biológico masculino, ni tampoco a la heterosexualidad masculina. Por otra parte, entendemos al ser hombre como: el referente de la masculinidad(es) que se manifiesta mediante los mandatos culturales de lo que un hombre debe hacer para ser considerado como tal en un contexto determinado.

\section{4.- Apuntes sobre el estudio de la(s) masculinidad(es)}

Probablemente el enfoque y teoría más influyente dentro del estudio de la(s) masculinidad(es) sea la propuesta de Connell (1995) y su masculinidad hegemónica $[\mathrm{MH}]$; se trata de una teoría general de género, pero ha tenido mayor implicancia en los estudios de masculinidades, debido a que pone en el centro de análisis a éstos y permite analizar la masculinidad como un modelo contextual, dinámico e histórico. La MH no es un tipo ideal weberiano, sino que es un modelo referencial que surge de la teoría gramsciana aplicada a los estudios de género. Ésta, parte del planteamiento de que el género es una de las formas de ordenamiento social, que funciona y se mantiene a través de la figura de la $\mathrm{MH}$, que sirve de referente o estrategia social que este ordenamiento utiliza para darse legitimidad. La MH actúa como una referencia cultural que da significado al sujeto hegemónico, personalizado en el patriarcado en la figura masculina del hombre, pudiéndose interpretar a la $\mathrm{MH}$ como el referente cultural de la masculinidad en las distintas sociedades patriarcales. A partir de esta teoría, muchas publicaciones han intentado remarcar las características que tiene dicho referente cultural hegemónico en los hombres, que en términos generales son las siguientes: heterosexualidad obligatoria; ser importante, tener fuerza física, invulnerabilidad, impulsividad y racionalidad; ser procreador, proveedor y jefe de familia; ser respetado, agresivo y no mostrar emocionalidad (Espinar-Ruiz y Ocampo, 2017). A su vez, otro aspecto importante de dicha masculinidad, radica en la importancia de la misma, pero ésta tiene una doble lógica para el hombre: por un lado se es importante por el simple hecho de ser varón, mientras que por otra parte, el hombre debe ser importante para poder ser considerado como tal (Marqués y Osborne, 1991). Esta ambivalencia, produce que autores como Bourdieu (2000) remarquen lo complejo que es para muchos hombres

6 En el apartado N7 (Discusión desde la propuesta de Estela Serret) se explica con mayor profundidad la propuesta de la autora. 
el ser hombre. En el plano simbólico, la masculinidad se definiría en función de su par dicotómico: la femineidad. En este sentido podemos afirmar que el proceso de creación social de la masculinidad tiene dos etapas: Se iguala todo lo que es masculino y por otro lado y al mismo tiempo, se lo diferencia de todo lo que es femenino (Marqués y Osborne, 1991).

Volviendo a la $\mathrm{MH}$ y sus distintas categorías, este modelo explicativo posee algunas críticas, sobre todo en el uso que se ha hecho del mismo en otras investigaciones. Por ejemplo, se mencionan los peligros de hablar de estas categorías modélicas como si se tratara de la masculinidad como un ente homogéneo (Núñez Noriega, 2007), de ahí que cada vez más se hable de masculinidades en plural. Hacer categorías ideales o esencialistas de lo que significa la masculinidad, no permite el análisis de las diferencias, no solo contextuales e históricas, sino interpersonales y subjetivas que están presentes en las identidades masculinas. Así mismo, si se coloca el modelo de $\mathrm{MH}$ que se utiliza en forma de categorías modélicas en el espectro de las denominadas sociedades posmodernas, encontramos que el sistema de referentes culturales con que se convive es múltiple y sumamente dinámico, produciendo una variabilidad muy importante en cuanto a las formas de ser hombre en la actualidad (Hatty, 2000). Demetriou (2001), propuso el concepto de masculinidades hibridas, donde el modelo hegemónico y los subordinados estarían en un constante proceso de hibridez, entremezclándose de tal manera que ya no serían evidentes las formas. En esta misma línea, Parrini (2016) explica que existe una disolución del vínculo entre lenguaje y realidad, que produce un laberinto de significados y prácticas que nunca coinciden, generando dispersión en los significados, los cuales se terminan volviendo las nuevas formas de dominación dentro del sistema sexo-género, por lo que los modelos tradicionales hegemónicos serían cada vez más dispersos y menos claros. Asimismo, Gutmann (2000) retrotrae el concepto de conciencia contradictoria de Gramsci, el cual habla de que existe en los imaginarios colectivos, una disputa entre presente y pasado, entre lo vivido y lo aprendido, dando lugar a una pluralidad de formas de prácticas contradictorias, lo cual también complejiza aún más el aspecto de la referencia masculina.

Pero al mismo tiempo, se manifiesta la importancia de definir al sujeto hegemónico, debido a que éste sigue siendo la norma de jerarquización de las sociedades patriarcales y que continúa otorgando privilegios a aquellos que la adhieren. En esta dirección, Núñez Noriega (2007) explica que en el nivel de lo simbólico, se puede hablar que aún persiste dicha hegemonía. Para este autor, no existe «el punto de vista de los hombres» como tal, pero sí un simbolismo de cierta forma de ser hombre que influye de manera tal, que genera que exista una relación entre «el ser hombre» $y$ tener un «punto de vista de hombre» a partir de concebir la «experiencia masculina» como una realidad homogénea.

\section{5.- Los hombres y las masculinidades en México}

Para cerrar el apartado de los estudios de género con enfoque en las masculinidades, cabe mencionar algunos aspectos específicos de estos estudios en México. 
Para el caso de México, hablar de una masculinidad mexicana sería un grave error, debido a la multiplicidad de contextos culturales, regionales, étnicos, generacionales y socioeconómicos existentes en el país. Lo mismo podríamos decir para la Ciudad de México. A pesar de eso, cabe remarcar algunas tendencias de estudios enfocados en hablar de características de las masculinidades mexicanas que vale la pena mencionar.

En primer lugar, el estudio de la masculinidad mexicana, surge de un interés de tipo antropológico, marcado por los relatos de Samuel Ramos y posteriormente de Octavio Paz y su Laberinto de la Soledad, textos que han esencializado la masculinidad mexicana como machista, en la cual se resalta la noción de la virilidad masculina (Machillot, 2013). En ésta, la figura del macho mexicano se vuelve un referente internacional, pero también a nivel interno en México. En este sentido, se explica que la masculinidad mexicana está marcada por el vínculo entre conquista, colonia y población nativa, en donde, México como nación, ha buscado imperiosamente poseer una identidad común (Gutmann, 2000). Esta identidad se gesta de la mano de la noción del macho, surgida del relato romántico sobre la revolución mexicana y sus distintos héroes (Domínguez Rubalcaba, 2013). Es así, que existe un proceso de construcción de la identidad nacional mexicana, muy vinculado a un proceso de gestación de cierto estereotipo de masculinidad, que contraen ciertos valores comunes entre ambos, en donde el machismo se vuelve un capital simbólico de la mexicanidad (Gutmann, 2000). Este hecho, también se vio acompañado de un proceso en el cual se fomentó mediante los espacios culturales, cierta representación de la masculinidad mexicana, marcada principalmente en la denominada era de oro del cine mexicano, con personajes que resaltaban una forma de ser hombre fuerte, rudo, valiente y romántico, reforzando el estereotipo de macho mexicano (González Marín, 2016). Este concepto del macho mexicano, es muy difuso en la actualidad, teniendo diferentes connotaciones, pudiendo poseer características tan dispares como el respeto, el honor, la violencia, la vigorosidad, el romanticismo y la emocionalidad (Gutmann, 2000).

Otro de los elementos que aparecen vinculados a la masculinidad mexicana, es la relación de la misma con la violencia. La relación entre masculinidad y violencia no compete únicamente a la realidad mexicana, sino que es marcada como parte de la propia lógica de la masculinidad a nivel histórico-espacial (Badinter, 1993). Para el caso de México, ésta relación tiene un claro vínculo con lo antes visto del estereotipo social del macho, que ha sido un referente cultural de la identidad masculina mexicana. Pero siguiendo a autores ya vistos como Guttman y Núñez Noriega, vemos que en la búsqueda de conformar una identidad mexicana masculina, hay una exacerbación de la virilidad y del resto de rasgos de la masculinidad tradicional. A su vez, se marca que la homofobia es parte también de ese ideario de masculinidad mexicana (Domínguez Rubalcaba, 2013), por lo que los hombres mexicanos tendrían mayores dificultades de mostrarse sensibles y vulnerables (por miedo a lo femenino y la homosexualidad) lo que los deja en una situación de mayor propensión a ejercer actos de violencia. En este sentido, el miedo a lo femenino, se traduce en que los hombres desde muy pequeños tengan que realizar rituales de 
iniciación y de paso con un fuerte carácter violento y misógino, que los va alejando de la emocionalidad y los acerca a la violencia (Echevarría Guzmán, 2013).

Un tercer eje de estudios se vincula a todo lo relacionado con la crisis económica y la crisis de masculinidad. Esta línea explica, que uno de los aspectos más importantes de la masculinidad mexicana pasa por su carácter de proveedor y sustento económico de la familia (Núñez Noriega, 2007; Jiménez Guzmán, 2013). En este sentido, el cambio en el modelo productivo-económico mundial, enmarcado en el neoliberalismo, dificulta que los hombres puedan realizarse como tal (Núñez Noriega, 2007), fomentando lo que algunos autores denominan como crisis de la masculinidad (Montesinos, 2002). Esta situación se da principalmente en los países latinoamericanos, debido a que está muy arraigada la noción del hombre proveedor (Jiménez Guzmán, 2013) y que las propias características socioeconómicas fomentan que este ideario no pueda ser fácilmente llevado a cabo (Connell, 2006). Esta crisis del rol de proveedor, fomenta que muchos hombres ejerzan violencia contra sus parejas mujeres (Jiménez Guzmán, 2013), debido a que existe el miedo a la pérdida de control sobre las mismas, al éstos no poder cumplir el rol que ellos creen que ellas les demandan (Seidler, 2006). A su vez, Parrini (2016), remarca que en México, existe una ética de la violencia y de la virilidad, aspecto que se puede apreciar por ejemplo en el aumento de la narco-violencia.

\section{6.- Análisis de los resultados}

El discurso surgido en la entrevista y los grupos, está marcado por diferentes maneras de entender la masculinidad en los usuarios, en donde intervienen las diferentes edades de los participantes, los niveles socioeconómicos y culturales de los mismos, así también, diferentes historias de vida relatadas. Pero, a pesar de la diversidad discursiva, aparecen algunos elementos comunes en los entrevistados, que nos dan lugar a trabajar una serie de categorías discursivas existentes ${ }^{7}$.

\section{Hombre no se nace, te hacen}

El ser hombre para los participantes aparece como una imposición desde el exterior, que empieza desde la niñez y continua hasta la actualidad, donde tanto la familia, como la sociedad, la cultura, el resto de hombres y también las propias mujeres, han exigido (y exigen) que los entrevistados tuvieran una serie de comportamientos para poder llegar a ser un hombre. Estos comportamientos los iremos viendo en los siguientes sub-apartados, pero lo interesante es que existe una clara conciencia de que ser hombre es algo que se les ha impuesto, por lo tanto, algo no natural. Esta reflexión lleva a los participantes a mencionar la existencia de códigos culturales que se introyectan en el sujeto: «somos una sociedad machista y muchas veces de manera imperceptible, como tan natural estos códigos de "no seas niña, no mames ma-

7 Es importante remarcar, que al estar estos hombres participando en un programa de reeducación de las conductas violentas, pueda existir una sobrerrepresentación de la violencia en el discurso que se hace sobre el ser hombre. 
nejas como niña, o manejas como vieja", todos estos códigos culturales que traemos» $(\mathrm{JU})^{8}$. A partir de la mención de dichos códigos, algunos entrevistados enumeran características correspondientes al «ser hombre» que se emparentan con algunas de las nombradas en el apartado teórico: «desde aquí te empiezas a dar cuenta de los estigmas y dogmas que traemos, no solo religiosos sino que culturales, el hombre se impone, el hombre controla, el hombre provee» (D). Estos mandatos del ser hombre van en dirección de ser «el más», pero también vinculados al rol de pareja, a la no emocionalidad y también al uso legítimo de la violencia, como veremos más adelante. Estas características, guían el discurso de los participantes y han marcado su manera de ser un hombre, afirmándose que ésta ha sido impuesta de la infancia, principalmente desde la propia familia y con el ejemplo de masculinidad del padre.

\section{En el nombre del padre}

Como se comentaba, el ser hombre se entiende como algo impuesto desde el exterior, existiendo una clara alusión a la cultura y sus códigos machistas como principal proveniencia. Pero, la forma en que estos códigos llegan a los hombres es por la vía familiar y principalmente por ejemplo y referencia del padre. Aquí sucede algo peculiar en los discursos de los participantes, en cuanto existen comentarios generalizados del rol que cumplen las madres en la enseñanza de los códigos machistas a los hombres en la sociedad, pero si nos centramos en los discursos de cómo cada uno de éstos han incorporado dichos códigos, ninguno hace mención a la madre y sí en cambio, la mayoría a la importancia que tuvo la imagen de su padre en el aprendizaje de cómo ser un hombre:

En un principio la idea con la que me formaron, en otras palabras, "ser macho», «ser cabrón» y «ser el pilar de tu familia», esa era la idea, lo que todo conlleva desde, si alguien ve a tu pareja en automático vas y le das sus trancazos o eres el que te puedes emborrachar y que puedes hacer lo que quieres, básicamente y no tener ningún reproche, en mi caso esa era la mentalidad con la que me forjé, en el ideal que me mostró mi padre (JU).

La figura del padre, funciona como referente para muchos de los entrevistados, quienes afirman que aprendieron a cómo comportarse a partir de su imagen. Este referente paterno, funciona en dos direcciones interconectadas: el uso de la violencia y la forma en cómo se debe ser el jefe de la familia. En cuanto a esta última, la representación vivida de los roles paternos y maternos ha sido clave para la formación identitaria de los entrevistados, quienes en su mayoría afirman el haber tenido un padre autoritario y una madre sumisa:

Pues yo pienso que la violencia es cultural, es conforme te enseñan desde chiquito, como le enseñaron a tus papás, como a tus abuelitos. Mi padre es muy autoritario, se hace lo que él dice, viven ahí sus hermanos a un lado, él siempre

8 Se nombra a cada participante con una letra diferente 
ha sido como que la cabeza, desde que falleció mi abuelito, su papá, como que él tomo el rol de jefe, jefe de en sí de mi familia, de sus hermanos y todos, entonces cualquier cosa que pasa pues él se hace como él lo dice. Entonces siempre yo lo viví así, así me enseñé (R).

Asimismo, en los relatos, aparece un vínculo muy importante al padre y el aprendizaje de la violencia y cómo ésta se termina volviendo un elemento clave en la representación que los participantes se han hecho desde pequeños del ser hombre. En este sentido, aparecen algunos relatos interesantes, que marcan cierto estado de complejidad que viven los sujetos con su referente masculino-paterno, con el cual tienen una relación de resentimiento, pero al mismo tiempo de deuda con el mismo:

Entonces todo ese tipo de conductas hoy reconozco que también vienen de atrás, desde mi nacimiento, desde mi adolescencia, debido a una acción de mi papá muy violenta hacia mí, muy violenta, me pegaba, yo me desquitaba con los compañeros que me hacían algo o sea era una vida muy fuerte pero yo no sabía esa etapa y hoy en día todavía mi papá ya al final, hace ocho años, lo perdoné en vida, platicamos él y yo y lo amo y lo quiero mucho también, me formó de una manera equis, a su entender porque él también llevaba una vida muy fuerte, más de lo que yo viví con él $(\mathrm{H})$.

Estos relatos, tienen cierto carácter contradictorio en el cual hay un resentimiento por la violencia vivida sobre ellos mismos y sobre sus madres, así como también, por haberlos convertido en el hombre que son ahora. Pero por otra parte, existe el entendimiento del porqué y las causas que llevaron al padre a ser el referente que fue, así como también, una cierta identificación y empatía éste, produciendo una cierta hermandad masculina con el mismo:

De alguna forma, nació uno y creció uno viendo todos esos episodios de violencia y se le hicieron muy comunes, entonces inconscientemente crece uno con esa mentalidad, de que lo que hizo tu padre lo vas a hacer también tú «yo voy a ser igual que mi papá» o sea nunca es de «vas a ser igual que tu mamá» porque si vas a ser igual que tu mamá o eres puto o ¿qué onda? tú vas a ser igual que tu papá (JO).

Es así que el ser hombre, para muchos de los participantes, queda supeditado a reproducir la imagen del padre, el cual se vuelve el referente identitario de género como contraparte del contra-referente femenino de la madre.

\section{Hombres en guerra}

Parafraseando a Max Weber, podemos decir que al hombre (al igual que al estado) se le adscribe y concede el uso legítimo de la fuerza y la violencia. A su vez, no solo es legítimo dicho uso, sino también necesario y hasta podríamos decir que obligatorio. Esta es la idea que la mayoría de los entrevistados manifiestan haber aprendido durante su infancia sobre la intrínseca relación entre el ser hombre y la violencia. Este vínculo y relación, se manifiesta principalmente desde la idea de 
que el hombre no debe ser sometido por ninguna otra persona, sea hombre o mujer. Este aprendizaje lo realizan contradictoriamente mediante el sometimiento ante la figura de su padre, quien como vimos, pone el ejemplo autoritario al niño en el camino hacia el ser hombre:

En mi familia, mi papá fue muy violento, muy violento con mi mamá, nunca me di cuenta de que le pegó pero siempre estaba esa amenaza de que «ya le va a pegar» y yo me metía entre ellos desde chiquillo hasta ya casado y todo le decía «No admito que tú le hables a mi mamá así», «Tú cállate. Y ipelas!». El trancazo de aquellos, de salir sangre y ese tipo de cosas y me golpeaba, entonces esa parte se queda en mi mente, en mi ser, entonces lo que me pasaba a mí era eso, yo me desquitaba con otros y era violencia, nada más me hacían tantito así o me veían «¿qué güey? ¿Qué me ves pendejo?» me desquitaba, a veces me iba bien, a veces me iba mal y realmente lo identifico en mi caso que eso es, esa cultura de que me echaban a pelear, como perrito «párate y rómpele la madre», «¿Por qué?» «Porque te lo estoy diciendo, por eso» E iba yo y puta, ya sabes, ¿no? Y salía uno bien y mis tíos o mi papá mismo «muy bien hijo, así es como se hace» $(\mathrm{H})$.

A partir de ahí, la vivencia del ser hombre para los entrevistados, se expresa como una constante demostración de su capacidad de poder y saber ejercer la violencia. En este sentido, los participantes en muchos casos, parecen narrar un estado de guerra constante entre hombres, en donde nunca se puede bajar la guardia, ya que si no se corre el riesgo de quedar expuesto como un no-hombre:

Y creo que yo como hombre, acá en México, es que así he sido educado, de tener que ser, de exponerme, de rifármela y decir bueno, a ver te tienes que exponer porque no le puedes dar cabida a esto que te comento, a que si me siento temeroso ante un momento donde un hombre me está retando, ese temor pues lo tengo que superar y ser valiente y ser un cabrón y órale (JU).

Este estado de vigía permanente, promueve que algunos participantes mencionen el déficit emocional que tienen, al no ser capaces de no poder no-reaccionar violentamente y a estar siempre a la defensiva: «es que también como hombres, nos han enseñado a "te hacen algo, te enojas; no te hacen algo, chido" son nuestras emociones» (D). Es así, que todos estos elementos afirman que el ser hombre y la violencia están ligados, y por lo menos desde este análisis, no se entiende uno sin el otro. Este componente de guerra constante tiene otro aliciente importante, que es la idea de que el hombre debe estar listo para proteger a «su mujer» todo el tiempo y de todo el mundo.

\section{El protector}

Un buen hombre es aquel que provee y protege a su mujer y su familia. Este parece ser el eslogan con el que crecieron la mayoría de los participantes, principalmente a través del ejemplo de su padre y su madre. En este sentido, los entrevistados manifiestan dos roles diferenciados pero intrínsecamente unidos: el de 
proveedor y el de protector. El segundo, continua lo expresado al final del apartado anterior, en cuanto a que el hombre tiene que estar en un estado de alerta constante, debido a que los otros hombres tienen la intención de robarle la mujer; por ese motivo, debe ejercer violencia ante la más mínima duda de que eso vaya a ocurrir «si yo no soy un cabrón, si yo no me aviento un tiro o bien si yo voy con mi pareja y le dicen algo y yo no brinco, yo no me expongo y decido aventarme un tiro pues termino siendo el puto, es algo que ya lo tenemos que hacer» (L).

Es así, que los participantes sienten la necesidad de mostrarse fuertes ante su pareja, reforzando así su hombría ante la mujer, quien éstos piensan y creen, que no solamente estará agradecida por el acto de valentía, sino que también estará exigiendo que éste se comporte de manera violenta: «me siento macho, me siento su hombre, me siento quien la puede defender y ese tipo de cosas, entonces yo soy violento también» $(\mathrm{H})$. Los entrevistados no solamente entienden que se reafirman como hombres al proteger a «su mujer», sino que también deben de proveerlas: «pues para mí toda mi vida pensé que el hombre era el que protegía a la familia, el que daba sustento, el que tenía que trabajar para mantenerla, que el hombre nunca llora, que yo mando, entonces para mí era eso» (R). El rol de proveedor también se aprende desde la infancia y se entiende como propio del ser hombre, pero en este caso, los participantes afirman no adscribirse completamente al mismo, consideran tener ideas igualitarias en cuanto a los roles que se deben tener en una pareja. En este sentido, aparecen una serie de valores nuevos, introducidos por algunas vivencias personales, tanto ya vividas en la familia en ese aspecto, como de intentos personales de no seguir esos pasos. A su vez, este discurso de igualdad en cuanto a los roles tradicionales de pareja, está ligado al proceso que llevan los participantes en el programa de GENDES, por lo que en este sentido se manifiestan muchos discursos de igualdad entre mujeres y hombres. A continuación veremos esto y otras nuevas formas de ser hombre que relatan los participantes.

\section{Hombres 2.0}

El discurso del ser hombre, está atravesado por el proceso vivido por los participantes en el programa reeducativo de GENDES. Es así, que aparecen múltiples comentarios, que por un lado, cuestionan muchos de los componentes antes vistos sobre la violencia, el rol del protector o la referencia del padre, así como también, plantean nuevas cuestiones surgidas de los procesos retro e introspectivos que cada uno de los entrevistados ha llevado a cabo durante todo su proceso en el programa. En este sentido, pareciera haber un antes y un después en la percepción que tienen los entrevistados del ser hombre, que busca romper con los códigos culturales antes comentados:

Antes de GENDES para mí ser hombre era un compromiso, era una obligación de destacar de ser siempre lo mejor, hacer lo mejor a cualquier precio o costo o por encima de quien fuese. Hoy en GENDES, para mí el ser hombre se me hace una palabra sin un compromiso, sino para mí sería el ser, o sea, ser nada más y poder hacer. Ya no con el hecho de que piense del compromiso, de la fuerza, 
de la obligación de destacar, de sobresalir de atraer, de proteger. Sino más de ser humano. Eso es para mí ser un hombre, ser un ser $(G)$.

Aparece en este renovado discurso, la idea de que ser un hombre es un ser humano más, marcando que no hay diferencias entre hombres y mujeres y a su vez, promoviendo un discurso de igualdad y respeto tanto ante la pareja como hacia el resto de la gente:

Sí me ha ayudado a cambiar mi perspectiva sobre mi idea esa de qué es ser un hombre, a verlo ya de una manera diferente, ser pues un hombre pero respetando también los derechos de los demás y sobre todo de mi pareja o sea darnos el mismo lugar que yo tengo, no por el simple hecho de que yo traiga esos códigos los tengo que ejercer forzosamente (M).

Buena parte de este discurso del nuevo hombre, está dirigido a la forma en cómo relacionarse con la pareja o las mujeres en general, pareciendo que el nuevo y diferente ser hombre lo es en función de la relación de pareja. Por otra parte, este proceso de deconstrucción o reconstrucción que los entrevistados, por lo menos a nivel discursivo, genera una serie de dudas sobre cómo ser un hombre sin dejar de serlo. Es decir, en este discurso aparece por un lado el miedo a que estos cambios que están buscando llevar a cabo les hagan perder su hombría y se queden en un limbo identitario, que los pueda conducir a algo no masculino, es decir, algo femenino:

Me da desconfianza de perder mi personalidad, no quiero perder mi tesón, soy muy tesonero, muy terco de que me pongo un objetivo y o sea lo tengo que lograr, entonces eso lo disfruto también pero luego pierdo mi identidad, me da mucha inseguridad de comunicarme con mujeres porque digo «no vaya ser que las esté yo violentando» $(\mathrm{F})$.

A su vez, aparece la dicotomía hombre nuevo, hombre viejo, en la que algunos participantes manifiestan encontrarse donde, siguiendo lo propuesto por Gutmann (2000) existe un conflicto entre los ideales aprendidos y los vividos y cómo estos se confunden en la práctica de los sujetos, generando también dudas en el proceso de reconstrucción del ser hombre:

Sí veo que hay modificaciones, pero a veces también estoy con la zozobra de que a partir de creer como esta parte «ya soy un nuevo hombre, ya no soy violento» creo que es un constante estar en guardia y no en esta forma de molestar y no de joder, sino que estar en guardia para mí y conmigo, como viéndome y confrontándome y estar alerta de mis señales, de lo que pienso, de lo que hago, de lo que actúo, estar como siempre alerta. $\mathrm{Y}$ a veces he bajado la guardia e igual vuelvo a ser el hombre viejo, porqué también he violentado (C).

En conclusión, estas categorías reflejan que para los participantes el ser hombre es algo que se impone culturalmente desde la niñez; en dicha imposición tiene un 
rol clave la figura paterna y a partir de ésta se inculca, en conjunto con el resto de la sociedad, la idea de que ser un hombre es ser violento, o mejor dicho, ser un hombre es no mostrar debilidad, lo que justifica el uso de la violencia.

\section{7.- Discusión desde la propuesta de Estela Serret}

El análisis desde la propuesta de Serret nos permite identificar el discurso del ser hombre como una categoría de género en sus tres niveles de interpretación. En el plano de lo simbólico, lo masculino se define en la contraposición a lo femenino, principalmente en algunos discursos relacionados con el hecho de la imposibilidad de tomar a la madre como referente, así como también en la separación que se hace de las prácticas y roles que un hombre y una mujer deben tener. El límite de la frontera identitaria se marca en el plano de lo simbólico, al entender que al traspasarla, automáticamente el hombre adquirirá la caracterización femenina, sin tener la capacidad de generar estructuras simbólicas por fuera de la dicotomía femenino/ masculino. Serret (2001), comenta que «La constitución de las identidades individuales y colectivas requiera de la inscripción del sujeto en un orden simbólico que organice y dé sentido a la percepción imaginaria» (2001: 91), siendo así que el dominio de lo simbólico se representa en lo cultural. En este sentido, para los participantes, la construcción del imaginario simbólico se representa en la obligatoriedad de no ser mujer, hecho que se representa en el ejercicio de la violencia que éstos relatan que han tenido que llevar a cabo, a modo de rituales de iniciación desde la infancia y que ya en etapa adulta, se mantiene en el rol del protector con el fin de no mostrarse como femenino. Así, se puede ver cómo simbólicamente la masculinidad se adquiere y se representa a través de una serie de procesos que llevan al sujeto a estar dentro de la frontera genérica masculina.

La definición de las mujeres o de lo femenino como frontera simbólica de lo que es ser un hombre, aparece marcada en la dicotomía padre/madre, en la cual hay una desidentificación con la segunda. Así también, la mujer se ve como el aspecto complementario del hombre, principalmente cuando los entrevistados hablan de la necesidad de tener una relación de pareja con una mujer a la cual proteger. En este sentido, el rol del protector, parece definirse a partir de la imagen de una feminidad débil y necesitada de protección, ante una masculinidad fuerte y protectora. Asimismo, el uso de la violencia que marca al ser hombre de los entrevistados, fomenta la idea que quien no la ejerce, recae en la figura del «puto», que aparece en algunos discursos como la imagen del no-hombre. Esta antítesis del ser hombre, encarna la feminidad en los cuerpos masculinos, siendo posiblemente el mayor miedo que tienen los entrevistados: miedo a pasar la frontera dicotómica de la masculinidad. Esto también puede ser entendido, como si la pérdida de la masculinidad no solamente supondría en el cambio a lo femenino, sino principalmente supone una pérdida del prestigio, y el pasar simbólicamente a ser seres subordinados y dependientes de otros seres masculinizados.

Si pasamos el análisis al nivel del imaginario social que propone Serret (2011), se asume que el nivel simbólico, genera un conjunto de normas comunes sobre lo 
que implica ser hombre o mujer. Es decir, este nivel se mueve en el espacio de lo referencial, siendo que en el caso de los entrevistados, el referente clave es el de la violencia, principalmente dirigida a no dejarse dominar por nadie, partiendo de la idea, de que siempre está presente la posibilidad de que alguien le pueda someter, hecho (el ser sometido) que se vincula a lo femenino y su esencia débil y dependiente de protección masculina. Para los entrevistados, las mujeres requieren y reclaman la protección del hombre autónomo, por lo que el imaginario social del hombre protector se mantiene en base al vínculo que mantiene con el imaginario de lo femenino. Pero por otra parte, los participantes no han afirmado que se suscriban al rol del proveedor, con el cual crecieron en la imagen referencial del padre. Éstos comentan que hoy en día los roles de la pareja han cambiado y que las mujeres también son capaces de ser proveedoras y que lo hombres deben «ayudar» ${ }^{9}$ en las tareas del hogar. Esto nos muestra que, para estos participantes, en el imaginario social del ser hombre existen transformaciones que rompen con elementos tradicionales como es el caso del rol del proveedor, que aparentemente deja de ser determinante en la construcción de la frontera identitaria del género, pero mantiene y refuerza otros como el del protector.

Volviendo a los referentes, los entrevistados han manifestado que la forma en que han aprendido a actuar como un hombre, ha sido a partir de la imagen del padre, quien aparece como el principal referente cultural de la masculinidad. De esta manera, los participantes crecen interiorizando estas normas de comportamiento, que terminan resultándoles naturales, normales y obligatorias, incorporándolas a sus cuerpos, acciones y pensamientos. En este punto, el imaginario social empieza entre-mezcladamente a dar lugar al nivel subjetivo del individuo, nivel que para Serret (2011), es la parte que describe la identidad del sujeto: «La autopercepción subjetiva, a la cual llamaremos con el nombre más indicativo de identidad, es siempre imaginaria, y como tal, compleja, contradictoria, cambiante, pero construida en la ilusión de coherencia, solidez y eternidad» (2001: 50).

El nivel subjetivo es el más volátil de los tres, pues la identidad está en una constante construcción a lo largo de todo el proceso de vida de la persona (Serret, 2011). Este nivel se mueve en función de la relación surgida en la interacción, en cuanto el yo del sujeto se construye en función del otro referente de la acción, siendo que la identidad tiene un fuerte carácter contextual. Pero, el nivel subjetivo, si bien está creado por el historial de interacciones de la persona, depende de los imaginarios sociales que generan tipificaciones de referentes conductuales, que a su vez están delimitados por el nivel simbólico, que vertebra, estructura y jerarquiza el orden social. El nivel subjetivo lo que genera es que el sujeto produzca y posicione al yo, creando la percepción que se tiene de uno mismo y de los otros generalizados (Serret, 2011). En el presente caso, la identidad subjetiva de los entrevistados se encuentra en un proceso de transición y conflicto, debido a la confrontación existente con los otros dos niveles. Esto se suma, a que a partir del proceso de reflexión

9 Para una revisión crítica del uso del término «ayudar» por parte de los varones para referirse a su rol en la labor doméstica, ver: BONINO MÉNDEZ, Luis (1996). «Micromachismos: la violencia invisible en la pareja». Primeras Jornadas de género en la sociedad actual. Valencia: Generalitat Valenciana, 25-45. 
producido en sus experiencias en el programa, donde los participantes ponen en duda muchas de las promesas del ser hombre que se les hicieron, llevando dicha reflexión a poner en cuestión algunos valores culturales existentes. Este proceso no es un proceso lineal ni sencillo, sino que está caracterizado por la presencia de lo que Gutmann (2000) denomina conciencia contradictoria, en cuanto hay un conflicto entre lo vivido y lo aprendido. Esto genera que los participantes tengan dudas sobre ¿qué o quién son? y ¿qué o quién van a ser? Al no existir otros referentes de masculinidad, los entrevistados no saben dónde posicionarse y tienen miedo de que al estar llevando a cabo cambios en sus ideas y acciones, éstas los lleven a perder su identidad masculina. Claramente, en los discursos el nivel subjetivo es el más afectado y cuestionado debido a la desestabilización del referente masculino, existiendo por un lado una ausencia de referentes a seguir al mismo tiempo que una sobrepresencia de los mismos, que se contradicen en cuanto a la valoración de lo vivido y lo aprendido.

\section{8.- Conclusiones}

El análisis del discurso de los entrevistados, muestra que la noción con la que éstos crecieron del ser hombre y de la masculinidad, está marcada en gran medida, por la socialización vivida en la infancia a partir de la imagen autoritaria del padre y sumisa de la madre, donde el carácter violento de la masculinidad, se relaciona en cuanto a la necesidad constante de demostración de la misma, por medio de la violencia competitiva. A su vez, esta noción se muestra como un espacio de constreñimiento y opresión, al mismo tiempo que otorga certezas y seguridad a los entrevistados. Este último punto se aprecia, al observar que éstos sufren el hecho de estar produciendo transformaciones en dicha noción, al dudar sobre su propia identidad masculina durante su proceso en el PCG. Así, el sistema sexo-género oprime y deja poco lugar al planteamiento de masculinidades alternativas, ya que se cae en el miedo de convertirse en el no-hombre, o sea alguien con características femeninas.

Como se vio en el apartado teórico de las masculinidades en México, las propias características histórico-culturales por las cuales se produce el ideario de nación y de masculinidad mexicana, están marcadas por un fuerte carácter homofóbico a partir de los relatos sobre los héroes de la revolución mexicana (Domínguez Rubalcaba, 2013). Este asunto se manifiesta en el discurso de los usuarios en cuanto al miedo en convertirse en un no-hombre a partir de la producción de cambios en las conductas relacionadas con la violencia, que se representan en la figura mencionada del "puto», que aparece como parte del imaginario social de lo que es ser un hombre, en este caso, a partir de la negación del mismo. En este sentido, se puede apreciar el peso del imaginario social en la subjetividad de los usuarios, respaldando el orden simbólico de género y no permitiendo que se puedan llevar a cabo transformaciones más profundas en las prácticas masculinas.

El modelo referencial hegemónico de masculinidad, se encuentra en un proceso de transformación en los discursos de los usuarios, en donde se contradicen los 
elementos aprendidos de la masculinidad con las nuevas prácticas subjetivas que se proponen desde el programa y desde ciertos contextos socioculturales. En este sentido las propuestas de Gutmann (2000) sobre las conciencias contradictorias, Demitriou (2001) y masculinidades hibridas o por Parrini (2016), en cuanto a la no coincidencia de las prácticas y los significados de género, se reflejan en el discurso de los participantes, donde la construcción de sus masculinidades se muestran como conflictivas debido a las incongruencias existentes entre los tres niveles de análisis de la categoría género propuestos por Serret (2001, 2011). Pero pese a este punto, también podemos afirmar al igual que Núñez Noriega (2007), que aún persisten elementos del modelo hegemónico en estos usuarios, que se sustenta en el nivel simbólico de la dicotomía femenino/masculino. De esta manera, la MH prevalece en el imaginario social, normatizando el deber ser masculino, homogenizando el punto de vista de la realidad masculina.

Se puede identificar principalmente, que existe una oposición entre los planos simbólicos y subjetivos de los usuarios, donde ocurre esta contradicción antes mencionada. En este sentido, se puede pensar, que una posible solución a este problema sería la de la mediación del nivel del imaginario social, por medio de la generación y valoración de referentes de masculinidad que se adecúen a estos procesos de cambio a nivel subjetivo. En la presente investigación, se identifica que para los entrevistados los referentes de las prácticas masculinas se mantienen estables, aunque existen cuestionamientos a cómo estos fueron aprendidos durante su infancia por medio de la imagen de sus padres. En este sentido, convendría incorporar la propuesta de Rita Segato ${ }^{10}$, en cuanto a que para poder «sacar» a los hombres del ejercicio de los mandatos tradicionales de masculinidad, se debe «atacar» por las fisuras que puedan existir en ésta, siendo que en los usuarios las principales fisuras aparecen en: la relación conflictiva con el padre durante la infancia; la erosión del rol de proveedor; y el fracaso de la vivencia de una masculinidad fallida.

Por lo tanto, comprender estos procesos por los cuales atraviesan los hombres en el programa de GENDES, permite entender que sí es posible generar un proceso reflexivo en cuanto a la noción de masculinidad en el plano subjetivo a partir del cuestionamiento de los imaginarios sociales, pero aún el carácter simbólico de la dicotomía femenino-masculino genera que la construcción de nuevas formas de masculinidad, se vea impedida por el riesgo y miedo a lo femenino, dificultando los cambios en las prácticas e ideas de los entrevistados. Este aspecto puede servir para comprender las dificultades que atraviesan los programas de intervención con hombres a nivel global, en donde prevalecen altos niveles de deserción, generados principalmente por la baja motivación que tienen éstos de trabajarse (Quiroz y Pineda-Duque, 2009; Autcher y Backes, 2013; Subirana-Malaret y Adrés-Pueyo, 2013; Ocampo, 2018). Se necesita entender, que los programas cumplen una importante función en cuanto a la reflexión y aceptación de las violencias ejercidas, así como de los orígenes de las mismas, pero se ven acotados, por un contexto social y cultural

10 CATEDRA TEOLOGÍAFEMINISTA. «Género y colonialidad. Día 4, 2a parte del Seminario de la Dra Rita Laura Segato». Video de YouTube, 51:12. Publicado el 23 de diciembre de 2018. https://www. youtube.com/watch?v=ji9ynbOpKrc 
que no permite la construcción de formas de masculinidad que rompan con los mandatos de género solventados en la dicotomía femenino/masculino.

\section{Bibliografía}

Alonso, Luis Enrique (2007). «Sujeto y discurso: El lugar de la entrevista abierta en las prácticas de la sociología cualitativa» en Delgado, Juan. Manuel y Javier Gutiérrez (eds.) (2012) Métodología y técnicas cualitativas de la investigación en ciencias sociales, Madrid: Sintesis, pp. 225-240

AmUCHÁstegui, Ana (2007). «El pensamiento sobre masculinidades y la diversidad de experiencias de ser hombre en México» en Amuchástegui, Ana y Ivonne SZASZ (eds.) (2007). Sucede que me canso de ser hombre: relatos y reflexiones sobre hombres y masculinidades en México, México DF: El colegio de México, pp. 15-38

Auchter, Bernard y Bethany Backes (2013). «NIJ's Program of Domestic Violence Research» en Violence Against Women, Vol.19, № 6, pp. 713-736.

BADINTER, Elizabeth (1993). XY: la identidad masculina, Madrid: Alianza editorial

Benítez Manuat, Raúl; Rodríguez Luna, Armando y Patricia Quintanar JIMÉNEZ (2018). "Violencia organizada y la persiste crisis de seguridad en México» en: Garza Hernández, Rafael. (eds.) (2018). Los retos de gestión de las violencias directas no políticas y la construcción de la paz, Barcelona: Institut Català Internacional per la Pau, pp. 195-226

Bourdieu, Pierre (2000). La dominación masculina, Buenos Aires: Anagrama.

Connell, Raewyn (1995). Masculinidades, México D.F: Universidad Nacional Autónoma de México, Programa Universitario de Estudios de Género

ConNell, Raewyn (2006). «Desarrollo, globalización y masculinidades» en Careaga Pérez, Gloria y Salvador Cruz Sierra (eds.) (2006). Debate sobre masculinidades: poder, desarrollo, políticas públicas y ciudadanía, México: UNAM, Programa Universitario de Estudios de Género, pp. 185-210.

Demetriou, Demetrakis (2001). "Connell's concept of hegemonic masculinity: A critique» en Theory and society, Vol. 30, N 3, pp. 337-361.

Domínguez Ruvalcaba, Hector (2013). De la sensualidad a la violencia de género. La modernidad y la nación en las representaciones de la masculinidad en el México contemporáneo, México: Ciesas

ECHEVARRÍA GUZMÁN, Genoveva (2013). «Vulnerabilidad en los varones mexicanos: fisuras y aperturas en las subjetivaciones masculinas» en RAMÍREZ RODRÍGUEZ, Juan Carlos y José Carlos Cervantes Ríos (eds.) (2013). Los hombres en México: veredas recorridas y por andar: una mirada a los estudios de género de los hombres, las masculinidades, Jalisco: Universidad de Guadalajara. 91-110

EspinaR-Ruiz, Eva e Ismael OcAmpo (2017). «Ways of Masculinity in Online Dating Profiles: The Cases of Meetic.es and AdoptaUnTio.es» en Masculinities and Social Change, Vol. 6, N³, pp. 196-216. 
GonzÁlez MARín, Daniel (2016). « ¿Es que no sabes que eres un hombre? Star system y Masculinidades en cinco actores del cine mexicano» en DE LOS REYES, Aurelio (ed.) (2016). Miradas al cine mexicano, vol. 1, México: IMCINE.

GuAsch, Oscar (2008). «Los varones en perspectiva de género. Teorías y experiencias de discriminación» en Asparkía. Investigació feminista, №19, pp. 29-38.

Gutmann, Mathew (2000). Ser hombre de verdad en la Ciudad de México: ni macho ni mandilón, México DF: El colegio de México.

Hatтy, Suzanne (2000). Masculinities, violence, and culture, Thousand Oaks, London and New Delhi: Sage

JimÉnEZ GuZMÁN, María Lucero (2013). «Reflexiones sobre ser proveedor en la crisis económica y del empleo. Impactos desde la perspectiva de género» en RAMírez Rodríguez, Juan Carlos y José Carlos Cervantes Ríos (eds.) (2013). Los hombres en México: veredas recorridas y por andar: una mirada a los estudios de género de los hombres, las masculinidades, Jalisco: Universidad de Guadalajara, pp. 53-70

LAGARDE Y DE LOS Ríos, Marcela (2007). «Por los derechos humanos de las mujeres: la Ley General de Acceso de las Mujeres a una Vida Libre de Violencia» en Revista Mexicana de Ciencias Políticas y Sociales, N²00, pp. 143-165.

MAchillot, Didier (2013). «El estudio de los estereotipos masculinos mexicanos en las ciencias humanas y sociales: un recorrido crítico-histórico» en RAMírez Rodríguez, Juan Carlos y José Carlos Cervantes Ríos (eds.) (2013) Los hombres en México: veredas recorridas y por andar: una mirada a los estudios de género de los hombres, las masculinidades, Jalisco: Universidad de Guadalajara, pp. 17-36

MArqués, Josep Vicent y Raquel Osborne (1991) Sexualidad y sexismo, Madrid: Fundación Universidad- Empresa

Montesinos, Rafael (2002). Las rutas de la masculinidad: ensayos sobre el cambio cultural y el mundo moderno, Barcelona: Gedisa

NúÑEz NoriegA, Guillermo (2007). «La producción del conocimiento de los hombres como sujeto genérico» en Amuchástegui, Ana y Ivonne SzAsz (eds.) (2007). Sucede que me canso de ser hombre: relatos y reflexiones sobre hombres y masculinidades en México, México DF: El colegio de México, pp. 39-72.

OсAмPO, Ismael (2018). Hombres que han ejercido violencia intrafamiliar: la deserción en un programa de intervención municipal en Montevideo, Uruguay. Multidisciplinary Journal of Gender Studies, Vol. 7, N³, pp. 1762-1785.

OlAVARria, José (2006). «Hombres e identidad de género: algunos elementos sobre los recursos de poder y violencia masculina» en CAREAGA PÉREZ, Gloria y Salvador CRUZ SIERRA (eds.) (2006). Debate sobre masculinidades: poder, desarrollo, políticas públicas y ciudadanía, UNAM: Programa Universitario de Estudios de Género, pp. 115-130.

ONU MUJERES (2017). «La violencia feminicida en México, aproximaciones y tendencias 1985-2016». Disponible en: https://www.gob.mx/conavim/ documentos / la-violencia-feminicida-en-mexico-aproximaciones-ytendencias-1985-2015 (Fecha de consulta: 09/10/18)

PARrini, Rodrigo (2016). Falotopías: indagaciones en la crueldad y deseo, Ciudad de México: Universidad Nacional Autónoma de México, Programa Universitario de Estudios de Género. 
Quiroz, Francisco y Javier PIneda Duque (2009). «Subjetividad, identidad y violencia: masculinidades encrucijadas». Universitas Humanística, №67, pp. 81103

Ruiz Olabuénaga, José Ignacio (1999). Metodología de investigación cualitativa, Bilbao: Universidad Deusto

Salguero Velázquez, María Alejandra (2013). «Masculinidad como configuración dinámica de la identidad» en RAmírez RodríGuez, Juan Carlos y José Carlos Cervantes Ríos (eds.) (2013). Los hombres en México: veredas recorridas y por andar: una mirada a los estudios de género de los hombres, las masculinidades, Jalisco: Universidad de Guadalajara, pp. 37-51

SEIDleR, Víctor (2006). «Masculinidad, hegemonía y vida emocional» en CAREAGA Pérez, Gloria y Salvador Cruz Sierra (eds.) (2006). Debate sobre masculinidades: poder, desarrollo, políticas públicas y ciudadanía, México: UNAM, Programa Universitario de Estudios de Género, pp. 147-158

SERRET, Estela (2001). El género y lo simbólico: la constitución imaginaria de la identidad femenina, México: UAM Azcapotzalco

SERRET, Estela (2011). «Hacia una redefinición de las identidades de género» en GénEros, Revista de investigación y divulgación sobre los estudios de género, Vol. 18, $\mathrm{N}^{\circ}$ 9, pp. 71-97

SubiranA-Malaret, Montse y Antonio Adrés-Pueyo (2013). «Retención proactiva $\mathrm{y}$ adherencia terapéutica en programas formativos para hombres maltratadores de la pareja» en Psychosocial Intervention, Vol. 22, N 2, pp. 41-53.

VALles, Miguel (1999). Técnicas cualitativas de investigación social: reflexión metodológica y práctica profesional, Madrid: Cultura libre

Recibido el 29 de enero de 2019 Aceptado el 4 de septiembre de 2019 BIBLID [1132-8231 (2019): 67-86] 